\title{
Oesophageal perforation subsequent to anterior cervical spine screw/plate fixation
}

\author{
M Hancı, M Toprak, AÇ Sarıoğlu, MY Kaynar, M Uzan and C Işlak \\ Istanbul University Cerrahpaşa Medical Faculty, Aksaray, Istanbul, Turkey
}

\begin{abstract}
We report three cases of oesophageal complications due to pressure necrosis secondary to screws post anterior plate fixation of the cervical spine. Two of the patients were treated using primary closure; and the third by conservative treatment, which consisted of wound drainage and an external orthotic device application. We recommend the early surgical closure and removal of the metallic implant with debridement as the first option of treatment. In the event that this option is not suitable, we suggest that wound drainage, tube feeding and parenteral antibiotics may be an appropriate alternative.
\end{abstract}

Keywords: anterior cervical osteosynthesis; plating and screws; complications; oesophageal perforation

\section{Introduction}

The use of an anterior approach to achieve arthrodesis of the cervical spine has become a widely accepted and frequently used approach ${ }^{1}$ since the earliest reports by Smith and Robinson ${ }^{2}$ and Cloward. ${ }^{3}$ The complications that may be associated with this procedure have, as a common factor, the close anatomical relation to the many vital structures in the neck. Oesophageal perforation can be a lethal complication of neck or chest trauma. ${ }^{4}$ The use of anteriorly applied grafts for an acutely unstable cervical spine can be fraught with complications; ${ }^{5}$ these include graft migration, and loss of anatomical correction, which creates instability. In the 1970s Orozco and Llovet ${ }^{6}$ tried to solve these problems by applying an anterior plate and screw fixation. It is advocated as a means to improve the overall union rate, and decrease the need for restrictive external immobilisation. ${ }^{7,8,9,10}$ However this technique has some particular complications such as oesophageal perforation. An oesophageal perforation following an anterior cervical surgical procedure is an uncommon but well recognised complication, and has been documented in the literature, but only by anecdotal case reports. ${ }^{11-15}$ Most are due to iatrogenic injury, inappropriate placement of retractors, delayed local vascular complications from excessive retraction, or pressure necrosis from implanted material..$^{11,15-17}$

\section{Case reports}

Case 1

A 22-year-old man was involved in a motor vehicle accident on 30 December 1989. He sustained a fracture of the body of the fifth cervical vertebra with a displaced bone fragment into the spinal canal. The neurological damage was com-

Correspondence: M Hancı, PO Box 792 8220, Şişli, İstanbul, Turkey plete (Frankel A) ${ }^{18}$ without sacral sparing. He underwent a corpectomy of the fifth cervical vertebrae and reconstruction from the fourth to the sixth cervical vertebra with a corticocancellous strut from the iliac crest. Postoperatively a Philadelphia collar was applied. On 21 January 1990 the graft became displaced; and on the same day the graft was reinserted and, to prevent re-dislocation, an anterior plate fixation with $4 \mathrm{~mm}$ cortical screws was performed. He was discharged on 15 February 1990 with complete C5 lesion. He was readmitted on 2 February 1991. The physical findings included a fluctuant red and painful mass in the left anterior aspect of the neck centred beneath a healed oblique skin incision and a spontaneous discharge of yellow green pus. On the day of admission emergency drainage was carried out and the plate and screws were removed. Marked scarring and dense fibrotic tissue were present. The oesophagus had obviously become perforated by the screws. Excision of the necrotic tissue and direct closure was performed. A nasogastric tube was inserted and enteral feeding was instituted. A postoperative radiograph showed osseous integration of the graft. On the 18th postoperative day, the patient was discharged home. His neurological condition was unchanged.

\section{Case 2}

A 22-year-old female was involved in a motor vehicle accident, sustaining a fracture of the body of the seventh cervical vertebra and bilaterally locked facets of C6-7 without neurological involvement (Frankel E). ${ }^{18}$ The locked facets could not be reduced by skeletal traction. The patient therefore underwent a bilateral facetectomy and posterior fixation of the vertebral spinous processes with stainless steel wires. During the same session a corpectomy of the seventh cervical vertebra and reconstruction from the sixth to the first thoracic vertebrae with a corticocancellous strut graft was applied and was secured using plate and screws. She was discharged 10 days later without neurological deficit. The patient was readmitted 47 days later with complaints of a sore throat and difficulty in swallowing, and a purulent discharge from the anterolateral aspect of her neck. Oral food intake was prohibited. She was 
given antibiotics parenterally and intravenous hyperalimentation was started. Three days later the local inflammation was noted to be less. She then underwent reexploration of the wound, in collaboration with the doctors from the otolaryngology department. The metallic implants were removed and the oesophagocutaneous fistula was repaired with the use of absorbable sutures. A nasogastric tube was positioned to bypass the perforated portion of the oesophagus. After a 2 week interval, the antibiotics and nasogastric tube were discontinued and the patient commenced oral feeding. At three years following the reoperation, the cervical spine was noted to be stable and there was no evidence of a fistula. Note: In patients 1 and 2, V2 EVRENR PL 3408 plates were applied (44 mm in length, $19 \mathrm{~mm}$ in width, $1 \mathrm{~mm}$ thick), DIN 17443 stainless steel and SCO 418 screws $(18 \mathrm{~mm}$ in length, $4 \mathrm{~mm}$ in diameter) of the same material.

\section{Case 3}

A 32-year-old female sustained a C5 fracture on 13 March 1994 without a spinal cord lesion (Frankel E). ${ }^{18}$ At an outside facility she underwent an anterior C5 corpectomy strut reconstruction and plate screw fixation. Two months later, the patient developed difficulty in swallowing and breathing due to an upper airway obstruction. A CT examination showed evidence of a large abscess (Figure 1). Emergency drainage was undertaken and the internal fixators were removed, but because of gross tissue inflammation and fragility, primary closure was not attempted. The area was debrided and irrigated and the wound was left open and packed with Betadine impregnated gauze. A gastrostomy was performed. Postoperative radiological investigations revealed the presence of an oesophagocutaneous fistula (Figure 2), destruction of the adjacent vertebral bodies, an epidural abscess and marked kyphosis (Figure 3). Culture of the pus grew MRSA and Pseudomonas aeroginosa. Appropriate antibiotics were started and a halo vest (Bremer ${ }^{\mathrm{R}}$ HT 025, AF102, Bremmer Medical Inc,

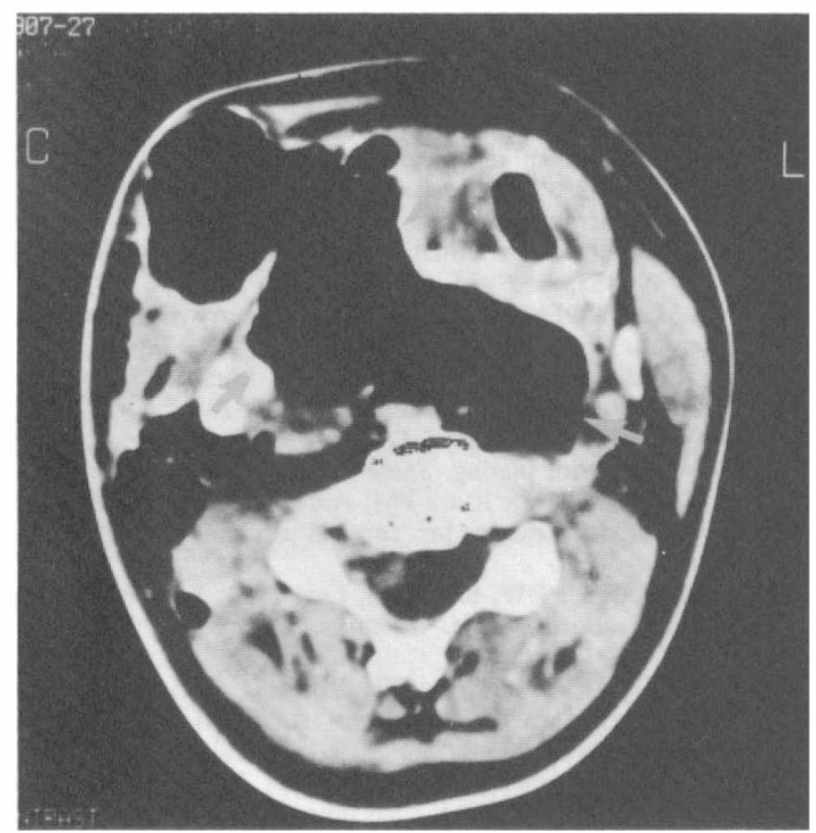

Figure 1 A preoperative axial CT scan shows large parapharyngeal abscess formation

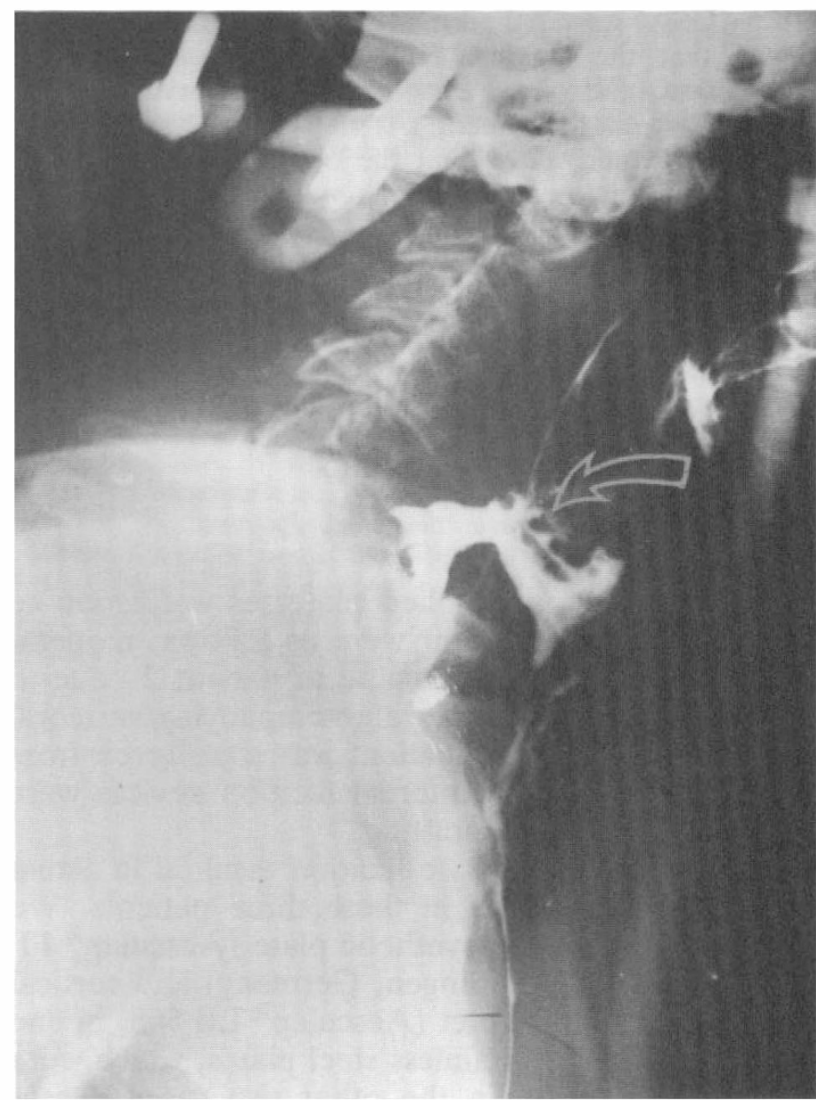

Figure 2 Barium meal swallow study shows oesophagocutaneous fistula. Note the leakage of contrast medium at the level of the fifth cervical vertebra

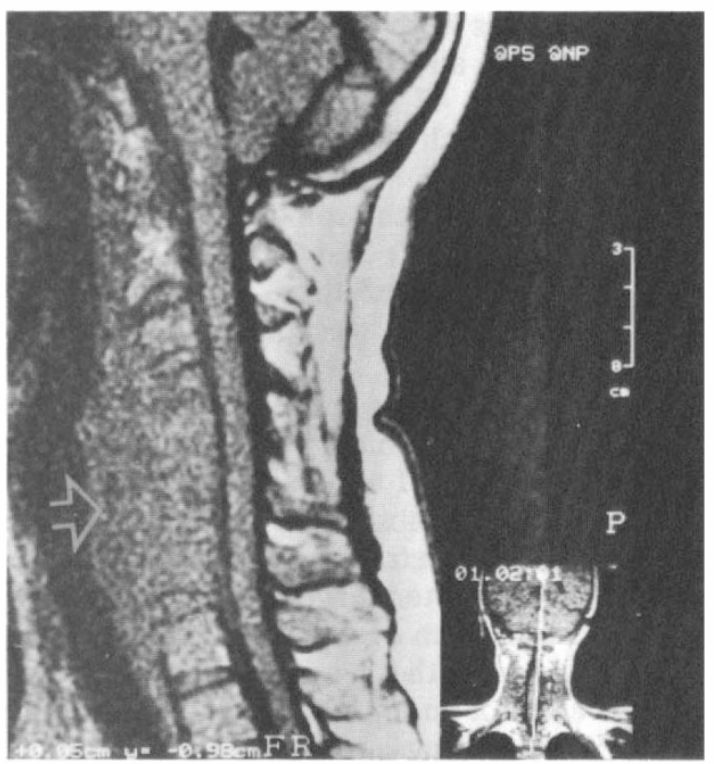

Figure 3 Contrast enhanced T1W sagittal MRI shows osteomylitic changes in the vertebral bodies and obvious kyphotic angulation 
Florida, USA) was applied for 16 weeks. Serial radiographs showed that the cervical spine regained alignment and spontaneous fusion was established. The cervical wound had healed without incident. At that time, a second contrast study demonstrated that the oesophageal perforation was completely closed. Seventeen weeks later the gastrostomy was closed. The patient has since done well with oral feedings and has returned to her previous job. Note: In this patient we used Aesculap ${ }^{R}$ LB $56 \mathrm{~S}$ screws $(16 \mathrm{~mm}$ in length, $3.5 \mathrm{~mm}$ in diameter) and FF $936 \mathrm{~S}$ plate $(44 \mathrm{~mm}$ in length, $19 \mathrm{~mm}$ in width, $1.2 \mathrm{~mm}$ thick), DIN 17443 stainless steel.

\section{Discussion}

The reasons that we applied plate/screw fixation to prevent graft dislodgement were as follows: reoperation of patient 1 ; unstable spine of patient 2-due to posterior ligamentous rupture accompanying vertebral body fracture; the third patient was transferred from another hospital where internal fixation devices were routinely added to strut grafting.

The use of anterior plate fixation resulted in actual oesophageal perforation in these three patients. We have used Caspar osteosynthetic plate (Aesculap ${ }^{\mathrm{R}} \mathrm{FF}$ 936, Aesculap AG, Tutlingen, Germany) and cortical screws of $3.5 \mathrm{~mm}$ diameter (Aesculap ${ }^{\mathrm{R}} \mathrm{LB}$ 56S) in one case and Caspar like stainless steel plates, which were produced in Turkey, in the other two cases. Oesophageal injury can occur some months after the time of the original arthrodesis due to oesophageal compression by the metallic implant itself ${ }^{11,15,16}$ as in our cases since there was no evidence of screw back-up.

Since the oesophageal perforations have been developed in 360, 47, 60 days after intervention, it was thought that these complications were not consequent to primary surgical trauma. We believe that oesophageal perforations were due to pressure sores caused by metallic implant and the microtrauma effect. The time variation (360, 47 and 60 days) in perforation development for each case can be explained by individual factors.

Since 1982, 264 cervical spinal injuries have been treated in our clinic. We have treated 137 of them surgically. Seventy one of these cases had anterior approach and in 32 cases we added plate/screw fixation.

The literature and our experience indicate that certain symptoms and clinical signs should alert clinicians to the possibility of an oesophageal perforation. There are usually no absolute pathognomonic signs of an oesophageal penetration injury. ${ }^{11,19}$ Neck pain, redness and swelling, tenderness and crepitus of the neck are indicative of an oesophageal injury associated with infection. Air in the cervical fascial spaces is an obvious indication of an injury to the upper aerodigestive system. These findings are especially alarming when the patient has had the application of metallic devices to the spine. All such patients require debridement and removal of the foreign material and another method of stabilising the spine if there is persisting instability. ${ }^{11,14}$
The treatment for oesophageal perforations continues to be highly controversial, revolving largely around the adequacy of medical versus surgical therapy. Sürgical therapy usually involves primary closure of the perforation. ${ }^{19-22}$ If an oesophageal perforation is detected intraoperatively the laceration if small can be primarily repaired. ${ }^{13} \mathrm{~A}$ nasogastric tube should be inserted and broad spectrum parenteral antibiotics should be started. This protocol usually results in oesophageal healing. If extensive loss of oesophageal tissue is noted, options include diversion or advancement with a primary oesophageal fistula. Occasionally the sternocleidomastoid muscle can be turned down as a localised muscle flap to provide vascularised coverage for the larger defects unsuitable for primary or advancement closures. ${ }^{23-25}$

We believe that an anterior cervical plate is indicated and can be useful in selected individuals, but we would restrict its use for those with severe anterior column instabilities which cannot be controlled by conventional stabilisation methods and halo immobilisation.

Oesophageal injury usually results from surgical exposure or from the metallic implant. Chronic compression of the oesophagus is considered to be the main cause of an oesophageal fistula, in spite of the appropriate closure of the prevertebral fascia.

We recommend early surgical closure and removal of the metallic implant with debridement as the first choice of treatment if it is possible. If not, conservative treatment with local drainage, administration of parenteral antibiotics and external orthotic support, and tube feedings may be a reliable alternative.

\section{References}

1 Caspar W. Anterior cervical fusion and interbody stabilization with the trapezial osteosynthetic plate technique. Aesculap Scientific Information: Tuttlingen, 1993, pp 2-67.

2 Smith GW, Robinson RA. Treatment of certain cervical spine disorders by anterior removal of the intervertebral disk and interbody fusion. J Bone Joint Surg Am 1958; 40: 607-623.

3 Cloward RB. Treatment of acute fractures and fracture-dislocations of the cervical spine by vertebral-body fusion. J Neurosurg 1961; 18: 201-209.

4 Colachis S, Murray KD. Oesophageal perforation: a delayed complication following traumatic spinal cord injury. Paraplegia 1992; 30: 449-453.

5 Tew JM, Mayfield FM. Complications of surgery of the anterior cervical spine. Clin Neurosurg 1976; 14: 492-494.

6 Orozco $\mathrm{R}$, Llovet $\mathrm{J}$. Osteosintesis en las fracturas des raquis cervical. Rev Ortop Traumatol 1970; 14: 285-288.

7 Aebi M, Zuber K, Marchesi D. Treatment of cervical spine injuries with anterior plating. Spine 1991; 16: S38-S44.

8 Caspar W, Barbier DD, Klara PM. Anterior cervical fusion and Caspar plate stabilization for cervical trauma. Neurosurgery 1989; 25: 491-502.

9 Mann DC, Brunner BW, Keene JS, Levin AB. Anterior plating of unstable cervical spine fractures. Paraplegia 1990; 28: 564-572.

10 Ripa DR, Kowal MG, Meyer PR, Rusin JJ. Series of ninetytwo traumatic cervical spine injuries stabilized with anterior ASIF plate fusion technique. Spine 1991; 16: S46-S55.

11 English GM, Hsu SF, Edgar R, Eccles MG. Oesophageal trauma in patients with spinal cord injury. Paraplegia 1992; 30: 903-912.

12 Kewalramani LS, Riggins RS. Complications of anterior spondylodesis for traumatic lesions of the cervical spine. Spine 1977; 2: 25-38. 
13 Kuriloff DP, Blugrand S, Ryan J, O'leary PJ. Delayed neck infection following anterior spine surgery. Laryngoscope 1987; 97: 1094-1098.

14 Smith MD, Bolesta MJ. Oesophageal perforation after anterior cervical plate fixation: a report of two cases. J Spinal Disord 1992; 5: 357-362.

15 Whitehill R, Sirna EC, Young DC, Cantrell RW. Late oesophageal perforation from an autogenous bone graft. $J$ Bone Joint Surg Am 1985; 67: 644-645.

16 Newhouse KE et al. Oesophageal perforation following anterior cervical spine surgery. Spine 1989; 14: 1051-1053.

17 Tomaszeck DE, Rosner MJ. Oesophageal perforation associated with cervical spine fracture. Neurosurgery 1984; 14: 492-494.

18 Frankel HL, Hancock DO, Hyslop G. The value of postural reduction in the initial management of closed injuries of the spine with paraplegia and tetraplegia. Paraplegia 1969; 7: 179-192.

19 Gussack GS. Penetrating face and neck trauma. In: Bailey BJ (ed). Head and Neck Surgery-Otolaryngology. JB Lippincott: Philadelphia, 1993, pp 1008-1017.

20 Cassisi NJ. Cervical trauma. In: Pillsbury HC, Goldsmith MM (eds). Operative Challenges in Otolaryngology-Head and Neck Surgery. Year Book Medical Publishers Inc: Chicago 1990; pp 497-512.

21 Keeling P. Oesophageal cutaneous fistula: a difficult problem made easy. Ir Med J 1983; 77: 108

22 Seiden AM. Oesophageal disorders. In: Paperella MM, Shumrick DA, Gluckmann JL, Meyerhoff WL (eds). Otolaryngology. WB Saunders Co: Philadelphia, 1991, pp 2439-2481.

23 Fuji $\mathrm{T}$ et al. Oesophagocutaneous fistula after anterior cervical spine surgery and successful treatment using sternocleidomastoid muscle flap. Clin Orthop 1991; 267: 8-13.

24 Goldstein LA, Thompson WR. Oesophageal perforations: a fifteen year experience. Am J Surg 1982; 143: 495-502.

25 Rubin JS. Sternocleidomastoid myoplasty for the repair of chronic cervical oesophageal fistula. Laryngoscope 1986; 96: 834-836. 